\title{
Pain management in the neonatal piglet during routine management procedures. Part 2 : Grading the quality of evidence and the strength of recommendations
}

\author{
A. $\mathrm{O}^{\prime}$ Connor $^{1 *}$, R. Anthony ${ }^{2}$, L. Bergamasco ${ }^{3}$, J. Coetzee ${ }^{1}$, S. Gould ${ }^{1}$, \\ A. K. Johnson ${ }^{1}$, L. A. Karriker ${ }^{1}$, J. N. Marchant-Forde, , G. S. Martineau ${ }^{5}$, \\ J. McKean ${ }^{3} \dagger$, S. T. Millman ${ }^{1}$, S. Niekamp ${ }^{6}$, E. A. Pajor ${ }^{7}$, K. Rutherford ${ }^{8}$, \\ M. Sprague ${ }^{9}$, M. Sutherland ${ }^{10}$, E. von Borell ${ }^{11}$ and R. S. Dzikamunhenga ${ }^{1}$ \\ ${ }^{1}$ Department of Veterinary Diagnostic and Production Animal Medicine, Iowa State University, \\ Ames, lowa, USA, \\ ${ }^{2}$ Philosophy Department, University of Alaska Anchorage, Alaska, USA, \\ ${ }^{3}$ Department of Animal and Poultry Sciences, Virginia Tech, Blacksburg, Virginia, USA, \\ ${ }^{4}$ USDA-ARS, Livestock Behavior Research Unit, West Lafayette, Indiana, USA, \\ ${ }^{5}$ National Veterinary School of Toulouse, Toulouse, France, \\ ${ }^{6}$ National Pork Board, Des Moines, lowa, USA, \\ ${ }^{7}$ Production Animal Health, University of Calgary, Calgary, Canada, \\ ${ }^{8}$ Scotland'd Royal College (SRUC), Edinburgh, United Kingdom, \\ ${ }^{9}$ American Association of Swine Veterinarians (AASV), Perry, lowa, USA, \\ ${ }^{10}$ AgResearch Ltd, Ruakura Research Centre, Hamilton, New Zealand, \\ ${ }^{11}$ Institute of Agricultural and Nutritional Sciences, Martin-Luther-University Halle-Wittenberg, \\ Halle, Germany
}

\section{Received 11 February 2014; Accepted 30 April 2014}

\begin{abstract}
Piglets reared in swine production in the USA undergo painful procedures that include castration, tail docking, teeth clipping, and identification with ear notching or tagging. These procedures are usually performed without pain mitigation. The objective of this project was to develop recommendations for pain mitigation in 1- to 28-day-old piglets undergoing these procedures. The National Pork Board funded project to develop recommendations for pain mitigation in piglets. Recommendation development followed a defined multi-step process that included an evidence summary and estimates of the efficacies of interventions. The results of a systematic review of the interventions were reported in a companion paper. This manuscript describes the recommendation development process and the final recommendations. Recommendations were developed for three interventions $\left(\mathrm{CO}_{2} / \mathrm{O}_{2}\right.$ general anesthesia, non-steroidal anti-inflammatory drugs (NSAIDs), and lidocaine) for use during castration. The ability to make strong recommendations was limited by low-quality evidence and strong certainty about variation in stakeholder values and preferences. The panel strongly recommended against the use of a $\mathrm{CO}_{2} / \mathrm{O}_{2}$ general anesthesia mixture, weakly recommended for the use of NSAIDs and weakly recommended against the use of lidocaine for pain mitigation during castration of 1- to 28-day-old piglets.
\end{abstract}

Keywords: Systematic review, animal welfare, swine, pain, castration, GRADE, piglets

\section{Introduction and background}

Consumers of animal products are increasingly interested in the ethical and social dimensions of food production

*Corresponding author. E-mail: oconnor@iastate.edu $\dagger$ Deceased 10 April 2014.
(Botonaki et al., 2006; Wright and Middendorf, 2008; Food and Agricultural Organization of the United Nations (FAO), 2009). Both collectively and individually, the American consumer has become more interested in the production history of food as a form of ethical consumerism (Singer et al., 2006). Recent public concerns regarding the need to protect farm animals have led to increased 
efforts to establish and enforce animal welfare regulations (Rauch and Sharp, 2005). Americans are concerned about farm animal welfare, and act on their concerns via voting initiatives and purchasing behaviors (Appleby, 2005; Tonsor and Wolf, 2010). In November 2006 voters overwhelmingly supported proposed animal welfare regulations that appeared on state ballots. Support for these regulations was often $\geq 60 \%$. Voters in California passed Proposition 2 in 2008, which regulates the housing of gestating sows, egg-laying hens, and veal calves. In 2009, a majority of voters in Ohio supported the establishment of a Livestock Care Standards Board (i.e. Issue 2) to provide oversight of farm animal care practices (Appleby, 2005; Singer and Mason, 2007; Tonsor and Wolf, 2010). The positive responses to these initiatives indicate that there is growing public demand for animal welfare assurance. Animal welfare assurance programs have been developed by food industry retailers, processors, producer groups, and private organizations. However, the US public appears to believe that external regulation is necessary. There is an apparent general lack of confidence that the industry will self-regulate, and a need for US animal industries to demonstrate that they are addressing animal welfare issues (Mench, 2003; Swanson, 2008). The increase in state-level initiatives may result in the development of federal farm animal welfare standards that exceed Animal Welfare Act standards. For the swine industry to retain its autonomy, a clear and coherent plan that includes the scientific and ethical issues fundamental to the animal welfare concerns of the public and of producer groups should be developed. This process begins with a critical assessment of accepted practices. This report presents the results of a process used to evaluate the scientific evidence and develop recommendations for pain mitigation in piglets in reared by the US swine industry. The objective of this project was to assess the efficacy of products designed to mitigate pain in piglets and to develop recommendations for their use.

During its first few days of life, a piglet reared by a US swine producer might be castrated, have its tail docked, its teeth clipped, and have notches or tags put into one or both ears. The reasons for the use of these procedures differ. Castration reduces boar taint and aggression as a pig matures to a market weight. Most of the pigs reared in pork-producing countries are castrated. Except for breeding stock, male swine are usually surgically castrated, but alternative methods are increasing in availability. Tail docking prevents pigs from biting the tails of their pen mates, but can result in tail infections, abscess formation, and in severe cases, paralysis or death. Management alternatives to tail docking that provide consistent results are not available. Teeth clipping reduces injury of mammary glands during nursing, and of littermates during teat competition. Teeth clipping was a common practice for many years, but has become less widely used by the industry. Ear notch identification is a unique means of individual pig identification for US breed registries. The US government uses information from ear notches to identify individual animals as they are moved during production. A swine producer may use ear notches to identify the animal's date of birth or other information useful for the management of individual or groups of pigs.

The procedures that are performed on piglets are considered to be painful for the animal. However, pain mitigation is not routinely provided to piglets reared in swine production in the USA. The reasons for this include historical precedent, economic barriers, impracticality, uncertainty about need, uncertainty about legality of the use of analgesic drugs, and uncertainty about efficacy. In response to the need for pain mitigation, the swine industry has funded research during the past decade to increase understanding about pain in piglets and to develop pain mitigation methods.

Piglet processing procedures involve surgery, so two phases of pain should be addressed during the use of an intervention (Kissin, 2000; Gottschalk and Smith, 2001). The pain that results from the incisional phase are primarily neutrally mediated (i.e. electrical pulses to receptors). The second, or prolonged inflammatory phase, arises primarily due to tissue damage and is mostly mediated by prostaglandin synthesis and cytokine release. The goal of administering analgesic compounds prior to castration is to mitigate both the incisional (general anesthesia, local anesthesia) and inflammatory (non-steroidal anti-inflammatory drugs (NSAIDs)) phases of the pain response (Ochroch et al., 2003). Among the interventions evaluated here, local and general anesthesia are interventions that relieve pain during the incisional phase. NSAIDs suppress inflammatory responses. Effective analgesia may require a multimodal approach using compounds that act on different receptor targets along the nociceptive pathway (Coetzee, 2013b).

\section{Approach to the development of recommendations}

Recommendation development is a multi-step process Oxman et al. (2006). Transparent development of guidelines ensures that stakeholders are aware of the factors that were considered during the process. The Grading of Recommendations Assessment, Development and Evaluation (GRADE) process was used during this project. Examples of guidelines developed using this approach have been published by the World Health Organization ${ }^{1}$, the American College of Physicians ${ }^{2}$, the Agency for Healthcare Research and Quality ${ }^{3}$, and the US Centers for

\footnotetext{
${ }^{1}$ http://www.who.int/influenza/human_animal_interface/ guidelines/pharmamanagement/en/

${ }^{2}$ http://www.gradeworkinggroup.org/publications/

Qaseem_ACP-COPD_Annals2007.pdf

${ }^{3}$ http://www.ahrq.gov/downloads/pub/evidence/pdf/phe/ phe.pdf
} 
Disease Control and Prevention ${ }^{4}$. The GRADE approach is also extensively described in a series of publications, and revised periodically (Balshem et al., 2011; Guyatt et al., 2011a, b, c, d, e, f, g, h, 2012, 2013a, b, c; Andrews et al., 2013a, b; Brunetti et al., 2013; Mustafa et al., 2013).

The GRADE approach was selected for this project because it is a transparent process and includes diverse and informed perspectives. The process acknowledges the importance of scientific evidence and the potential for biased scientific information. It articulates ethical and non-ethical values and preferences that motivate recommendations. A key concept in the development of recommendations is that scientific evidence is global, but decisions are local. Scientific evidence is considered to be global in that if reviewers use the same approach for searching, extracting, and analyzing data during the review process, they typically arrive at the same conclusions. Decision making is local in that it is informed by local challenges, values, and preferences, and by the limitations of a particular review process.

Recommendations are also affected by time and available data and expertize. Changes in dynamic factors (e.g. scientific evidence, social values, and preferences) affect the balance of benefits and harms, so resource allocation may change over time. The recommendations developed during this project are a result of the current state of knowledge, expertize, and resource availability.

Previously described approaches were used to develop our recommendations (Schunemann et al., 2006b; Guyatt et al., 2011g). The process consisted of 19 parts: (1) establish priorities, (2) establish group composition and consultations, (3) declare and avoid conflicts of interest, (4) define group processes, (5) identify important outcomes, (6) define the questions and eligibility criteria, (7) determine study designs for different questions, (8) identify evidence and clarify basic assumptions, (9) synthesize and present evidence, (10) specify and integrate values and preferences, (11) make judgments about desirable and undesirable effects, (12) take account of equity, (13) grade the evidence and recommendations, (14) account for costs, (15) adapt, apply, and transfer guidelines, (16) determine report structure, (17) determine methods of peer review, (18) plan dissemination and implementation methods, and (19) evaluate the guidelines (Schunemann et al., 2006b).

\section{Scope of the recommendations and evidence considered}

The original project objective was to provide a total of 12 recommendations for the use of three interventions (general anesthesia, NSAIDs, and local anesthesia) for four procedures (castration, tail docking, teeth clipping,

${ }^{4}$ http://www.cdc.gov/vaccines/recs/acip/GRADE/about.htm and identification with ear notching or tagging). A systematic review was performed to identify scientific information to be used in the recommendation process (Dzikamunhenga et al., 2014).

The results of the systematic review revealed that there were few data available for some topics. Data were often reported in a format that precluded summary and quantification of results. Consequently, the steering committee chose to present data from seven outcomes at two time points (i.e. $<60 \mathrm{~min}$ and $1-24 \mathrm{~h}$ after a procedure) for consideration during the recommendation-making process. The outcomes were cortisol, norepinephrine, and $\beta$-endorphin concentrations, frequency or pitch $(\mathrm{Hz})$ of vocalizations, energy or loudness $(\mathrm{dB})$ of vocalizations, vocalization rate or risk (the number of vocalisations per piglet per unit time during and after castration, or the percent of piglets that vocalized), and frequency of pain-associated behaviors.

Only two studies (from the same publication) that assessed pain mitigation related to teeth clipping and ear notching were identified during the review. Because this amount of data was insufficient for the development of recommendations, these procedures were not included in the process.

Only the results from trial arms (i.e. the group of piglets receiving a certain type of therapy) using a single pain mitigation strategy were included in the development of recommendations. Publication of more than one study from two or more authors was also necessary for an intervention to be included in the recommendations.

Because of the limitations imposed by these criteria, the scope of the recommendation making process was narrower than originally intended. Three areas were included in the recommendations. They were use of $\mathrm{CO}_{2} /$ $\mathrm{O}_{2}$ general anesthesia, use of lidocaine, and use of NSAIDs, during castration of piglets. For these three areas, there was sufficient number of independent studies for only eight possible outcomes (Table 3). We developed an evidence profile, a summary of findings table, and a recommendations table for each intervention (as suggested by GRADE guidelines).

\section{Methods and processes for recommendation development}

Recommendations and guidelines for numerous animal production topics are available e.g. euthanasia (https:// www.avma.org/KB/Policies/Documents/euthanasia.pdf; biosecurity (https://webadmin.pork.org/filelibrary/Biosecurity/final\%20biosecurity\%20book.pdf_)). However, examples of transparent approaches to the formal incorporation of scientific information into the development of recommendations are not available. The procedures used during development of the recommendations are usually not described. This information may not be necessary for some non-controversial topics. However, experience 
Table 1. Expertize sections identified as necessary for the GRADE guidelines-making process, and the steering committee and external panel members in each section

\begin{tabular}{|c|c|}
\hline Expertize & Participant and institution \\
\hline Applied animal behavior & $\begin{array}{l}\text { Anna Johnson (lowa State University, USA) }{ }^{1,2} \\
\text { Suzanne Millman (lowa State University, USA) } \\
\text { Jeremy Marchant-Forde (USDA-ARS, USA) } \\
\text { Ed Pajor (University of Calgary, Canada) })^{2,3} \\
\text { Kenny Rutherford (Scotland's Rural College, UK) }{ }^{2,3}\end{array}$ \\
\hline $\begin{array}{l}\text { Animal and agricultural ethics } \\
\text { Food production economics } \\
\text { Pharmacology }\end{array}$ & $\begin{array}{l}\text { Raymond Anthony (University of Alaska Anchorage, USA) })^{2,3} \\
\text { Glynn Tonsor (Kansas State University, USA) } \\
\text { Johann (Hans) Coetzee (Iowa State University, USA) })^{1,2} \\
\text { Kip Lemke (University of Prince Edward Island, Canada) }\end{array}$ \\
\hline Stress physiology & $\begin{array}{l}\text { Sherrie Niekamp (National Pork Board, USA) })^{2,1} \\
\text { Luciana Bergamasco (Virginia Tech, USA) }{ }^{2,3} \\
\text { Mhairi Sutherland (AgResearch Ltd, New Zealand) })^{2,3} \\
\text { Eberhard von Borell (Martin-Luther-University Halle-Wittenberg, Germany) })^{3,4}\end{array}$ \\
\hline Study design and sources of bias & $\begin{array}{l}\text { Annette O'Connor (lowa State University, USA) })^{1,4} \\
\text { Rungano Dzikamunhenga (lowa State University, USA) } \\
\text { Locke Karriker (lowa State University, USA) } \\
\text { Hans Coetzee (lowa State University, USA) } \\
\text { Han }^{1,2}\end{array}$ \\
\hline Swine health and production & $\begin{array}{l}\text { Gene Noem (Murphy Brown Inc., USA) }{ }^{2,3} \\
\text { Brent Scholl (Scholl Farms, USA) } \\
\text { Locke Karriker (Iowa State University, USA) })^{2,1} \\
\text { Jim McKean (lowa State University, USA) } \\
\text { Guy Martineau (Ecole Nationale Veterinaire de Toulouse, France) }{ }^{2,3} \\
\text { Michelle Sprague (American Association of Swine Veterinarians, USA) }{ }^{2,3}\end{array}$ \\
\hline $\begin{array}{l}\text { Research synthesis and guideline } \\
\text { development }\end{array}$ & Annette O'Connor (lowa State University, USA) \\
\hline
\end{tabular}

Explicitly targeted stakeholder groups

Animal welfare NGO

Not represented (four individuals from four organizations were invited, all declined to participate)

Organized veterinary medicine

Michelle Sprague (American Association of Swine Veterinarians, USA)

Swine producer

Gene Noem (Murphy Brown Inc., USA)

Brent Scholl (Scholl Farms, USA)

\footnotetext{
${ }^{1}$ Steering committee member.

${ }^{2}$ Voting panel member.

${ }^{3}$ External participant.

${ }^{4}$ Review team member.
}

from human health disciplines suggests that there is value in adding such information so that end users are aware of the process used for decision-making. The following sections provide details about the development of the recommendations that resulted from this project.

\subsection{Priority setting}

Priorities for development of a set of recommendations are often established by a steering committee (Oxman et al., 2006). In 2011, the National Pork Board Animal Welfare Committee published a 5-year research strategy to address the swine industry's animal welfare priorities. Pain management during piglet processing was identified as a research priority. The National Pork Board Animal Welfare Committee requested a literature review of piglet processing procedures and pain management.

\subsubsection{Group composition and consultation process} There were four groups of project participants (i.e. steering committee, review team, external participants, and panel members). Some of the participants were members of more than one group (Fretheim et al., 2006a) (Table 1). External participants were invited to attend the recommendation development meeting. The panel members were also members of the steering committee or were external participants, and had voting rights during the meeting. The review team consisted of A. O'Connor, R. Dzikamunhenga, and S. Gould. The review team members did not vote.

The steering committee determined the content, methodological expertize, and stakeholder groups needed during the project (Fretheim et al., 2006a) (Table 1). Although published recommendations suggest that group size should be limited to 15 members (Fretheim et al., 2006a), the steering committee recommended inviting 25 people. The final panel meeting group consisted of 19 voting members. Four nongovernmental organizations associated with animal welfare groups were invited to attend the February 2013 meeting, but none were able to participate.

Project funding was received in August 2012, and the review protocol was completed in December 2013. 
The steering committee meetings were in September 2012 (Steering Meeting 1) and January 2013 (Steering Meeting 2). The panel meeting was at the Renaissance Hotel, Des Moines, Iowa, USA, from 12-14 February 2013 (2.5 days). The panel meeting was chaired by the review coordinator, Dr A. O'Connor (the facilitator).

\subsubsection{Managing conflicts of interest}

Conflict of interest statements were not required prior to invitation or participation, but were required prior to publication. The list of authors included only the participants who provided a conflict of interest statement.

\subsubsection{Group processes}

Group processes, the voting approach, and document preparation followed published recommendations (Fretheim et al., 2006b). Decisions made at steering committee meetings (September 2012 and January 2013) were made after discussion, but without formal voting. At the February 2013 panel meeting, confidential voting and vote tallies were completed using automated clickers. At the panel meeting voters could not abstain, and a $\geq 75 \%$ majority was required for approval of a recommended intervention.

\subsubsection{Identification of important outcomes for recom- mendation making}

The steering committee identified and nominated relevant outcomes before the systematic review was initiated (Dzikamunhenga et al., 2014). The list of outcomes was shared with the external participants. They were also invited to suggest additional outcomes. There were four categories on the final list: behavioral outcomes (during and within $60 \mathrm{~min}$ of a procedure), behavioral outcomes (1-24 h after a procedure), non-behavioral outcomes (during and within $60 \mathrm{~min}$ of a procedure), and nonbehavioral outcomes (1-4 h after a procedure) (Table 2).

In November 2012, panel members ranked the outcomes (one (least important) to nine (most important)) by completing an online questionnaire (SurveyMonkey) (Guyatt et al., 2011c). Critical outcomes were assigned values of 7-9. These outcomes were essential to the decision-making process. In the context of this review, critical outcomes were those for which it was clear that the outcome was a measure of pain experience rather than other responses, such as stress or fear. Similarly, these may have been outcomes that more directly measured the animal's response in a cascading pathway. For example, cortisol leads to a stress leukogram; therefore, cortisol would be the more direct measure. Important outcomes were assigned values of 4-6. Important outcomes were less essential to the decision-making process. Non-important outcomes were assigned values of 1-3. Non-important outcomes were defined as outcomes that were unlikely to change the decision-making process or inference. These outcomes are often measured because the data are simple to collect or are part of standard practice. However, they were not considered to be truly relevant for the assessment of an intervention, and were not included in the guideline development process. The results of the survey were summarized after outcome data were extracted from the literature.

Note that one of the weaknesses of our ranking process was that original survey designed by the review team grouped the outcomes together for all procedures. Although for general stress responses such as cortisol these would all be expected to occur in each procedure. The behavioral outcomes were more likely specific i.e. wound guarding depends on the location of the insult, and visceral pain responses associated with castration, but not tail docking, etc. Similarly, ear flicking was ranked highly but this is almost certainty because it was considered important for ear notching. This likely resulted in lower ranking of the behavioral outcomes and reflects an error in the survey methodology.

\subsubsection{Explicit definition of the question and eligibility criteria}

Dzikamunhenga et al., (2014) describes the systematic review methodology. The parts of the review were determined $a$ priori and were described in a protocol. The steering committee prepared the protocol. The specific review question was, 'In piglets that undergo castration, tail docking, teeth clipping, and/or methods of identification that involve cutting of the ear tissue, such as ear tagging and ear notching $(\mathrm{P})$, what is the effect of pain mitigation (I) compared with no pain mitigation (C) on behavioral (e.g. postures, vocalizations) and non-behavioral (e.g. blood cortisol, norepinephrine, and $\beta$-endorphin levels) indicators of pain assessed within $60 \mathrm{~min}$ of the procedure and between 1 and $24 \mathrm{~h}$ of performing the procedure $(\mathrm{O})$ ?' All outcomes were extracted, regardless of the panel members' rankings.

\subsubsection{Identification of evidence}

Descriptions of the search for evidence, screening for relevant studies, and data extraction procedures are presented in (Dzikamunhenga et al., 2014).

\subsubsection{Synthesis and presentation of evidence for the panel meeting}

During the January meeting (after data extraction was completed), the steering committee decided which outcomes would be included in the guideline development process. The results of the ranking exercise and the review data extraction process, including the frequency values for the outcomes of interest, were reported to the steering committee (Dzikamunhenga et al., 2014). The steering committee made four key decisions at this meeting. First, only two studies from the same publication were available for teeth clipping and ear notching. The committee decided that this was an insufficient amount 


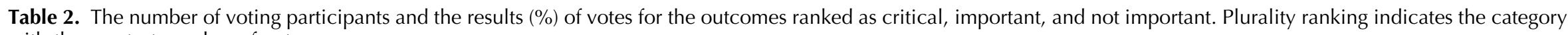
with the greatest number of votes

\begin{tabular}{|c|c|c|c|c|c|}
\hline Outcomes & $n$ & Critical (\%) & Important (\%) & Not important $(\%)$ & Plurality ranking \\
\hline \multicolumn{6}{|l|}{ Behavioral outcomes (<60 min) } \\
\hline Vocalization, call duration & 11 & 27 & 55 & 18 & Important \\
\hline Vocalization, call rate & 10 & 10 & 60 & 30 & Important \\
\hline Vocalization, main frequency (pitch) & 11 & 45 & 45 & 9 & Critical/important \\
\hline Vocalization, peak amplitude & 10 & 60 & 30 & 10 & Critical \\
\hline Vocalization, peak frequency (pitch) & 11 & 64 & 27 & 9 & Critical \\
\hline Activity event, defecation & 9 & 0 & 33 & 67 & Not important \\
\hline Activity event, escape attempts & 11 & 36 & 36 & 27 & Critical/important \\
\hline Activity event, urination & 9 & 0 & 22 & 78 & Not important \\
\hline Activity state, lying & 9 & 0 & 56 & 44 & Important \\
\hline Activity state, playing & 10 & 30 & 30 & 40 & Not important \\
\hline Activity state, running & 9 & 0 & 33 & 67 & Not important \\
\hline Activity state, sitting & 9 & 0 & 33 & 67 & Not important \\
\hline Aggression event & 9 & 0 & 44 & 56 & Not important \\
\hline Conditioned avoidance testing & 9 & 0 & 11 & 89 & Not important \\
\hline Body movement event, ear flicking & 11 & 27 & 55 & 18 & Important \\
\hline Body movement event, head shaking & 11 & 27 & 55 & 18 & Important \\
\hline Body movement event, rear end movement such as kicking, scratching & 11 & 27 & 64 & 9 & Important \\
\hline Feeding event, suckling/nursing & 10 & 10 & 30 & 60 & Not important \\
\hline Feeding event, teat seeking/udder mouthing & 9 & 11 & 44 & 44 & Important/not important \\
\hline Feeding event, teeth champing/chewing & 9 & 22 & 44 & 33 & Important \\
\hline \multicolumn{6}{|l|}{ Non-behavioral outcomes $<60 \mathrm{~min}$} \\
\hline Adrenocorticotrophic hormone (ACTH) & 8 & 13 & 50 & 38 & Important \\
\hline Beta endorphins & 7 & 29 & 57 & 14 & Important \\
\hline Body temperature & 7 & 29 & 57 & 14 & Important \\
\hline Cortisol & 9 & 11 & 56 & 33 & Important \\
\hline Electrocardiograph readings (ECG) & 8 & 25 & 63 & 13 & Important \\
\hline Electroencephalogram readings (EEG) & 8 & 50 & 38 & 13 & Critical \\
\hline Epinephrine & 8 & 25 & 50 & 25 & Important \\
\hline Haptoglobin & 8 & 0 & 25 & 75 & Not important \\
\hline Heart rate & 9 & 33 & 44 & 22 & Important \\
\hline Norepinephrine & 8 & 38 & 50 & 13 & Important \\
\hline Respiratory rate & 9 & 22 & 67 & 11 & Important \\
\hline Substance P & 8 & 50 & 13 & 38 & Critical \\
\hline \multicolumn{6}{|l|}{ Behavioral outcomes (1-24 h) } \\
\hline Vocalization, call duration & 9 & 0 & 22 & 78 & Not important \\
\hline
\end{tabular}




\begin{tabular}{|c|c|c|c|c|c|}
\hline Outcomes & $n$ & Critical (\%) & Important (\%) & Not important $(\%)$ & Plurality ranking \\
\hline Vocalization, call rate & 9 & 11 & 11 & 78 & Not important \\
\hline Vocalization, main frequency (pitch) & 9 & 11 & 22 & 67 & Not important \\
\hline Vocalization, peak amplitude & 9 & 11 & 22 & 67 & Not important \\
\hline Vocalization, peak frequency (pitch) & 9 & 11 & 11 & 78 & Not important \\
\hline Activity event, defecation & 10 & 0 & 30 & 70 & Not important \\
\hline Activity event, escape attempts & 9 & 0 & 22 & 78 & Not important \\
\hline Activity event, urination & 10 & 0 & 20 & 80 & Not important \\
\hline Activity state, lying & 11 & 27 & 45 & 27 & Important \\
\hline Activity state, playing & 11 & 55 & 36 & 9 & Critical \\
\hline Activity state, running & 11 & 36 & 55 & 9 & Important \\
\hline Activity state, sitting & 11 & 27 & 45 & 27 & Important \\
\hline Aggression event & 9 & 0 & 22 & 78 & Not important \\
\hline Conditioned avoidance & 10 & 40 & 20 & 40 & Critical/not important \\
\hline Body movement event, ear flicking & 10 & 40 & 40 & 20 & Critical/important \\
\hline Body movement event, head shaking & 11 & 36 & 36 & 27 & Critical/not important \\
\hline Body movement event, rear end movement such as kicking, scratching & 11 & 36 & 45 & 18 & Important \\
\hline Feeding event, suckling/nursing & 11 & 45 & 36 & 18 & Critical \\
\hline Feeding event, teat seeking/udder mouthing & 11 & 27 & 55 & 18 & Important \\
\hline Feeding event, teeth champing/chewing & 10 & 20 & 60 & 20 & Important \\
\hline \multicolumn{6}{|l|}{ Non-behavioral outcomes, $1-24 \mathrm{~h}$} \\
\hline Adrenocorticotrophic hormone (ACTH) & 8 & 25 & 63 & 13 & Important \\
\hline Beta endorphins & 7 & 29 & 57 & 14 & Important \\
\hline Body temperature & 7 & 29 & 57 & 14 & Important \\
\hline Cortisol & 9 & 33 & 33 & 33 & All \\
\hline Electrocardiograph readings (ECG) & 8 & 13 & 50 & 38 & Important \\
\hline Electroencephalogram readings (EEG) & 8 & 13 & 50 & 38 & Important \\
\hline Epinephrine & 7 & 14 & 29 & 57 & Not important \\
\hline Haptoglobin & 6 & 50 & 33 & 17 & Critical \\
\hline Heart rate & 7 & 14 & 43 & 43 & Important/not important \\
\hline Norepinephrine & 7 & 14 & 43 & 43 & Important/not important \\
\hline Respiratory rate & 6 & 0 & 67 & 33 & Important \\
\hline Substance P & 7 & 43 & 29 & 29 & Critical \\
\hline
\end{tabular}


of information, and declined to continue data analysis and recommendation development for these procedures. Second, only the results of trial arms with a single pain mitigation strategy were to be included in the review. For example, if piglets in one arm received lidocaine (local anesthetic) and meloxicam (NSAID), the results of that arm were excluded. This decision affected the inclusion of protocols that included combined use of ketamine and azaperone, or these drugs combined with others (e.g. meloxicam).

The third committee decision was that the following outcomes were the only ones to be summarized for the panel meeting: cortisol, norepinephrine, $\beta$-endorphins, vocalization $(\mathrm{Hz})$, energy $(\mathrm{dB})$, rate, and pain-associated behaviors, all at $<60 \mathrm{~min}$ or between 1 and $24 \mathrm{~h}$ of the procedure. The rationale for presenting these outcomes was included because they were ranked as important, and data were available. The intervention types were categorized as general anesthetic, local anesthetic, and NSAID.

The fourth committee decision was that the outcome 'pain-related behaviors' would be defined after data extraction with the assistance of an expert in applied animal behavior. This approach was necessary because multiple parameters were often reported in the literature, but were not always identified as specific outcomes in the original publication. Multidimensional pain scales have been identified as more accurate characterizations of the complexity of an animal's pain experience (Rutherford, 2002). Therefore, the animal behavior expert preferentially selected the pain index score as the pain behavior outcome when authors consolidated pain behaviors into an aggregate pain index score. We randomly selected one behavior outcome within pain-associated behaviors when this information was not provided. Pain-related behaviors were identified as those that would be expected to occur in the presence of pain, to be absent or occur at low frequencies in the absence of pain, and to be reduced or eliminated in the presence of effective anesthesia or analgesia (Millman, 2013), such as motor patterns associated with avoidance or removal of noxious stimuli in the home pen (e.g. wound licking) or in specific nociception tests (e.g. response to von Frey filaments or pressure algometry). For example, the review team was advised to assume that behavior responses directed to the rear quarters (tail flinching, tail wagging, tail rubbing, kicking, scooting, and easing the quarters) would be more sensitive measures of pain resulting from castration and tail-docking surgeries; hence, we randomly selected a behavior outcome from this group of responses. The logic for selecting a single outcome from this group of behaviors was twofold. First, this was a time-consuming process since variability in terminology and behavior observation protocols required each paper to be careful read to ensure extraction of the correct behavior and units based on the ethograms used. Second, we wanted to avoid duplication of what is essentially the same category of outcome, similar to the logic for our selection of cortisol as the most common glucocorticoid biomarker vs. other candidate molecules (e.g. ACTH).

We acknowledge that changes to time budgets associated with recuperative behavior or 'sickness motivation' (Aubert, 1999) are likely to occur post-surgery, resulting in reductions in feeding and exploratory motivation and increased rest. However, methodology for collecting time budget behaviors was highly variable between studies, and there is little basic knowledge for how these behaviors would be expected to change during illness. For example, rest typically increases as part of the sickness behavior cascade following pro-inflammatory cytokine release (Millman, 2007). However, disruptions in rest patterns also occur in response to acute pain, making meta-analysis of this variable impossible. Hence, many of the behavior outcomes collected during pain experiments are at the discovery stage of research during which the a priori predictions for response are absent. Furthermore, in some experiments feeding and resting behaviors were collected with the objective of investigating effects of productivity versus pain per se, and hence experiments were not necessarily designed for this latter question. For these reasons, changes in time budget behaviors were not extracted for our analysis.

At the February panel meeting, the panel members received a summary of the literature search, a list of outcomes extracted from the literature, the results of the online outcome ranking survey, and forest plots of 14 outcomes (RevMan, 2012). Each member also received a tabulated summary of each outcome (Guyatt et al., 2013c).

\subsubsection{Specification and integration of values}

The GRADE process was designed for use in human health. Because we modified it for use for this animal welfare topic, we clarified the identification of the target audiences for assessment of benefits and harms, and for assessment of values and preferences (Schunemann et al., 2006a). These concepts were discussed at a steering committee meeting in January, 2013. At that meeting it was decided that the panel meeting would include a discussion of these topics with the recommendation that (1) the balance of benefits and harms for outcomes be measured in piglets, and (2) the values and preferences be of the public consumers of pork and citizens (i.e. voters).

At the February panel meeting, these ideas were discussed again after two presentations that clarified this aspect of the recommendation-making process. Dr Raymond Anthony (University of Alaska Anchorage) presented, 'Integrating science into socio-ethical deliberations on animal welfare and care policy: how can instruments like GRADE help to mitigate pain in farmed pigs?', which reviewed epistemological and normative considerations related to the attitudes of the US public toward animal welfare and broader societal concerns (food security, safety, environmental soundness of animal 
agriculture). He also discussed the importance of the use of the GRADE process to address values and preferences in a climate of ethical pluralism, risk, and uncertainty. Dr Glynn Tonsor (Kansas State University) presented information on the economics of animal welfare issues. Dr Glynn Tonsor discussed differences between voter (citizen) and consumer preferences, manifest and theoretical willingness to pay, and manifest and theoretical cost to adopt. Both presentations included discussions of potential biases present in the evidence base. Systematic reviews of the values and preferences of consumers and citizens were not included in the presentations. The speakers proposed that more research is needed to understand, (a) consumer and citizen perceptions of onfarm management processes, (b) public opinions about the relationship between ethical attitudes toward animals and their welfare, and what the public considers to be an acceptable quality of life for farmed animals, and (c) what drives the relative desirability for alternative animal production practices among the different public sectors that consume animal protein and byproducts.

\subsubsection{Making judgments about desirable and unde- sirable effects}

The meeting clarified that benefits and harms would be considered in terms of outcomes that affected the pig, and that the target audience with respect to values and preferences would be pork consumers and citizens.

\subsubsection{Taking account of equity}

Taking account of equity not explicitly considered.

\subsubsection{Grading evidence and recommendations}

The GRADE working group recommended the approach used to evaluate the quality of the evidence (Balshem et al., 2011; Guyatt et al., 2011a, b, c, d, e, f, g, h, 2013a, b, c; Andrews et al., 2013a, b; Brunetti et al., 2013). The GRADE system separates the process of grading scientific evidence to inform recommendations from the process of making recommendations. Scientific evidence is graded based on the presence or absence of inconsistency, indirectness, imprecision, and risk of bias in the evidence base that contributes to each outcome. Characteristics of an inconsistent evidence base include a wide variation in point estimates, lack of overlap between confidence intervals, and evidence of heterogeneity among studies. An evidence base displays indirectness when the study populations, interventions, or outcomes used in the primary research differ from those defined for the review. An evidence base is imprecise if results include wide confidence intervals, which indicates that sample sizes were not large enough to obtain adequate study power. Risk of bias is present in an evidence base if studies fail to report blinding or allocation concealment, do not account for all subjects, experience a large loss of subjects to follow up, selectively report outcomes, use biased recruitment methods, stop the study early, or use invalidated outcome measures. For this project, the panel only considered risk of bias resulting from failure to control for confounding. However, to ensure the exchangeability of study groups, study designs were required to include (when relevant) randomization, stratification for categorical factors (e.g. sow, litter), and blocking for continuous factors (e.g. weight, age).

The panel members developed an evidence profile for each procedure and intervention combination. All participants voted on the following domains for each outcome associated with each intervention and procedure: Risk of bias (Low or Serious or Very Serious), Indirectness (Low or Serious or Very Serious), Inconsistency (Low or Serious or Very Serious), Imprecision (Low or Serious or Very Serious), Evidence of publication bias (Undetected or Strongly Suspected).

If the panel members did not achieve a consensus, the panel was informed and the discussion continued. The facilitator often invited participants to explain their reasons for a particular vote or to discuss the GRADE term further. Group members voted again after this discussion. If a consensus could not be achieved, the vote was delayed, and other issues were discussed and voted upon. This process continued until all outcomes for each procedure and intervention combination were assessed (Table 3).

The panel used the voting results to develop recommendations. The body of evidence was downgraded for domains in the serious category. The body of evidence was upgraded when control for confounding, a large effect size, and evidence of a dose-response relationship were present. An evidence grade for each outcome resulted from this process. The grades were (language used by the GRADE working group):

- High quality: further research is very unlikely to change our confidence in the estimate of effect.

- Moderate quality: further research is likely to have an important impact on our confidence in the estimate of effect and may change the estimate.

- Low quality: further research is very likely to have an important impact on our confidence in the estimate of effect and is likely to change the estimate.

- Very low quality: we are very uncertain about the estimate.

The panel did not achieve a consensus for 'imprecision' on many occasions during the evidence grading phase. Significant time and effort were applied to understand the definition of imprecision. The facilitator suggested that decisions about imprecision should consider the number of studies, and the widths of the confidence intervals. Evidence of imprecision was present if confidence intervals included different clinical implications. Two rankings were used to account for this issue. For example, if the panel could not reach consensus, and the votes were divided between 'Serious' and 'Very Serious,' 
Table 3. GRADE voting results expressed as percentages for the outcomes and interventions considered for recommendations

\begin{tabular}{|c|c|c|c|c|c|c|c|c|}
\hline & \multicolumn{3}{|c|}{$\mathrm{CO}_{2} / \mathrm{O}_{2}$ general anesthesia } & \multirow{2}{*}{$\begin{array}{l}\text { Local anesthesia } \\
\text { Energy } \\
(0-60 \mathrm{~min})\end{array}$} & \multicolumn{4}{|c|}{$\underline{\text { Non-steroidal anti-inflammatory drugs }}$} \\
\hline & $\begin{array}{l}\text { Cortisol } \\
\text { (0-60 min) }\end{array}$ & $\begin{array}{l}\text { Cortisol } \\
(1-24 \mathrm{~h})\end{array}$ & $\beta$-endorphins & & $\begin{array}{l}\text { Cortisol } \\
(0-60 \text { min })\end{array}$ & $\begin{array}{l}\text { Cortisol } \\
(1-24 \text { h) }\end{array}$ & $\begin{array}{l}\text { Energy } \\
(0-60 \text { min })\end{array}$ & $\begin{array}{l}\text { Pain-like behaviors } \\
(0-60 \mathrm{~min})\end{array}$ \\
\hline \multicolumn{9}{|l|}{ Risk of bias } \\
\hline Low & 17 & 11 & 11 & 75 & 100 & NC & 82 & 94 \\
\hline Serious & 83 & 83 & 89 & 25 & 0 & NC & 12 & 6 \\
\hline Very serious & 0 & 6 & 0 & 0 & 0 & NC & 6 & 0 \\
\hline \multicolumn{9}{|l|}{ Indirectness } \\
\hline Low & 83 & 83 & - & - & - & - & - & - \\
\hline Serious & 6 & 17 & - & - & - & - & - & - \\
\hline Very serious & 11 & 0 & - & - & - & - & - & - \\
\hline \multicolumn{9}{|l|}{ Inconsistency } \\
\hline Low & 6 & 83 & 83 & 75 & 94 & 83 & 83 & 83 \\
\hline Serious & 89 & 17 & 17 & 19 & 6 & 11 & 17 & 11 \\
\hline Very serious & 6 & 0 & 0 & 6 & 0 & 6 & 0 & 6 \\
\hline \multicolumn{9}{|l|}{ Imprecision } \\
\hline Low & 11 & 17 & $\mathrm{NC}$ & NC & 83 & 94 & $\mathrm{NC}$ & NC \\
\hline Serious & 89 & 83 & $\mathrm{NC}$ & $\mathrm{NC}$ & 17 & 6 & $\mathrm{NC}$ & NC \\
\hline Very serious & 0 & 0 & $\mathrm{NC}$ & NC & 0 & 0 & NC & NC \\
\hline \multicolumn{9}{|l|}{ Publication bias } \\
\hline Undetected & 83 & 94 & - & - & 89 & 100 & 83 & 89 \\
\hline Strongly suspected & 17 & 6 & - & - & 11 & 0 & 17 & 11 \\
\hline \multicolumn{9}{|l|}{ Body of work } \\
\hline Very low & 94 & - & $\mathrm{NC}$ & 94 & 6 & - & - & - \\
\hline Low & 0 & - & NC & 6 & 89 & - & - & - \\
\hline Moderate & 6 & - & NC & 0 & 6 & - & - & - \\
\hline High & 0 & - & NC & 0 & 0 & - & - & - \\
\hline \multicolumn{9}{|c|}{ Absence of high-quality evidence } \\
\hline Yes & 100 & - & - & - & 88 & - & - & - \\
\hline No & 0 & - & - & - & 12 & - & - & - \\
\hline \multicolumn{9}{|l|}{ Benefits and harms } \\
\hline Yes & 76 & - & - & 81 & 12 & - & - & - \\
\hline No & 24 & - & - & 19 & 88 & - & - & - \\
\hline \multicolumn{9}{|l|}{ Values and preferences } \\
\hline Yes & 100 & - & - & Yes? & 88 & - & - & - \\
\hline No & 0 & - & - & & 12 & - & - & - \\
\hline \multicolumn{9}{|l|}{ Recommendation } \\
\hline For & 0 & - & - & 25 & 82 & - & - & - \\
\hline Against & 100 & - & - & 75 & 18 & - & - & - \\
\hline \multicolumn{9}{|c|}{ Recommendation strength } \\
\hline Weak & 6 & - & - & 88 & 82 & - & - & - \\
\hline Strong & 94 & - & - & 12 & 18 & - & - & - \\
\hline
\end{tabular}


and we considered this uncertainty during the subsequent voting stage.

After an evidence profile was developed for each outcome that related to a procedure and intervention outcomes, the participants then voted about the entire body of work for each procedure and intervention i.e. they considered how the intervention affected multiple outcomes together:

(1) Quality of body of work (Very low or Low or Moderate or High)

(2) Absence of high-quality evidence (Yes or No)

(3) Uncertainty about the balance of benefits and harms (Yes or No)

(4) Uncertainty about the values and preferences (Yes or No)

After establishing these evidence profiles for each outcome, and grading all outcomes combined for each procedure and intervention, the panel voted on the following:

(5) For or against the intervention (For or Against), and then

(6) The strength of the recommendation (Weak or Strong).

After voting was completed, the GRADEpro® (2008) summary of findings, evidence profiles, and recommendations tables were completed.

\subsubsection{Taking account of costs}

Panel members included economics during consideration of values and preferences. The economic costs of interventions must be absorbed somewhere along the farm-to-fork continuum (i.e. by producers, packers, food processors, retailers, and/or consumers/citizens). These costs affect consumer willingness to pay and producer willingness to adopt an intervention. The process of considering resources and costs included weighting the economic costs and benefits to the public and producers, and weighting the relative costs against each other for these stakeholder groups. Panelists did not include product availability during the consideration of values and preferences because resource implications were added to the judgment. This discussion was mostly limited to the factors that affect the legal availability of products. For example, some products were not registered for use for pain mitigation in piglets in the USA, but they were registered for use in many other countries (e.g. Canada, Mexico, New Zealand, and the European Union)

\subsubsection{Adaptation, applicability, transferability of guidelines}

Our goal was to provide the evidence and protocol in a format that would enable others to use the evidence. The final report provided to the funding agency included a description of the protocol. The information provided in this manuscript also represents a component of the transfer process.

\subsubsection{Structure of reports, methods of peer review, planned methods of dissemination, and implementa- tion and evaluation of the guidelines}

The review team created a draft report that described research gaps, guideline development, and translation issues. All steering committee members reviewed and edited this draft. It was then shared online for comment from the external participants. After the end of the comment period, the Iowa State University steering committee met to discuss the comments, and members were assigned parts of the review for finalization: research gaps, guideline development, and translation issues. The review team then combined the three sections into a final report, shared it with the external participants for comment, and then submitted it to the funding agency. The review team then prepared publications for peerreview.

\subsubsection{GRADE and systematic review training for panel participants}

Opportunities for panelists to become familiar with the process of systematic review and guideline development were provided several times prior to the panel meeting:

(a) The review facilitator provided the steering committee with a presentation about research synthesis and recommendation development at each full-day planning meeting.

(b) The review process protocol was distributed for comment from the participants.

(c) The steering committee and the external participants (except for the economist and the producers) were required to verify the validity of the extracted data for several papers included in the review.

(d) A video tutorial described the data extraction software and approach.

(e) Four 5- to 15-min tutorial videos were available online 7 days prior to the panel meeting. These tutorials described the GRADE approach and the criteria for panel member selection.

(f) Evidence synthesis and recommendation development were discussed during the first half of the panel meeting. The topics included identification of sources of bias in scientific research, how to read a metaanalysis forest plot, and a description of the domains used to evaluate research quality: bias, consistency, imprecision, indirectness, publication bias, magnitude of effect, the potential direction of confounding bias, and evidence of a dose-response effect. The discussion also included a description of the domains used for recommendations: quality of evidence, values and preferences, balance of benefits and harms to the individual, and resource implications. 
Table 4. Summary of findings, $\mathrm{CO}_{2} / \mathrm{O}_{2}$ anesthesia during castration

\begin{tabular}{|c|c|c|c|c|}
\hline Outcomes & Illustrative comparative difference in outcomes* $(95 \% \mathrm{Cl})$ & $\begin{array}{l}\text { No. of animals } \\
\text { and studies reporting } \\
\text { the outcome }\end{array}$ & $\begin{array}{l}\text { No. of animals and } \\
\text { studies included in } \\
\text { the meta-analysis }\end{array}$ & $\begin{array}{l}\text { Quality of the } \\
\text { evidence (GRADE)** }\end{array}$ \\
\hline Cortisol (60 min) & $\begin{array}{l}\text { The mean cortisol within } 60 \text { min of castration } \\
\text { was } 33.97 \text { higher in the intervention groups } \\
\text { ( } 95 \% \mathrm{Cl}=57.41 \text { lower to } 125.35 \text { higher })\end{array}$ & 240 (five studies) $^{1-3}$ & 208 (three studies) $^{1-3}$ & $\begin{array}{l}\oplus \ominus \ominus \ominus \ominus \\
\text { Very low }\end{array}$ \\
\hline Cortisol $(24 \mathrm{~h})$ & $\begin{array}{l}\text { The mean cortisol } 1-24 \mathrm{~h} \text { after castration was } \\
59.97 \text { lower in the intervention groups }(95 \% \\
\mathrm{Cl}=92.78-27.17 \text { lower })\end{array}$ & 220 (four studies) $)^{1,3}$ & 188 (two studies) $)^{1,3}$ & $\begin{array}{l}\oplus \oplus \ominus \ominus \\
\text { Moderate/low }\end{array}$ \\
\hline$\beta$-endorphin (60 min) & $\begin{array}{l}\text { The mean } \beta \text {-endorphin within } 60 \text { min of castration was } \\
1.06 \text { higher in the intervention groups }(95 \% \mathrm{Cl}=0.66 \\
\text { lower to } 2.78 \text { higher })\end{array}$ & 115 (four studies) $)^{2,3}$ & 115 (two studies) $)^{2,3}$ & $\begin{array}{l}\oplus \oplus \ominus \ominus \\
\text { Moderate/low }\end{array}$ \\
\hline
\end{tabular}

"The basis for the assumed risk (e.g. the median control group risk across

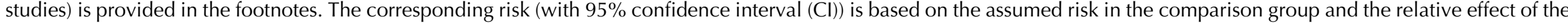
intervention (with 95\% Cl).

"GRADE Working Group grades of evidence

High quality: further research is very unlikely to change our confidence in the estimate of effect.

Moderate quality: further research is likely to have an important impact on our confidence in the estimate of effect and may change the estimate.

Low quality: further research is very likely to have an important impact on our confidence in the estimate of effect and is likely to change the estimate.

Very low quality: we are very uncertain about the estimate.

${ }^{1}$ Randomized, not blinded, and blocked.

${ }^{2}$ Randomized, not blinded, and not blocked.

${ }^{3}$ Not randomized, not blinded, and not blocked.

${ }^{4}$ One study showed a positive effect, favoring the intervention; the other point estimate was positive, but the $95 \%$ interval included the null value, 0.

${ }^{5}$ Concern about the width of the interval. 
(g) Presentations about values and preferences were also included in the meeting.

\section{Recommendations}

\subsection{Intervention: general anesthesia $\left(\mathrm{CO}_{2} / \mathrm{O}_{2}\right)$}

The panel's current position is a strong recommendation against the use of a $\mathrm{CO}_{2} / \mathrm{O}_{2}$ general anesthesia mixture for pain mitigation during castration of 1- to 28-day-old piglets.

\subsubsection{Discussion of recommendation for general anesthesia $\left(\mathrm{CO}_{2} / \mathrm{O}_{2}\right)$}

Carbon dioxide mixed with oxygen to provide $\mathrm{CO}_{2} / \mathrm{O}_{2}$ anesthesia was the only inhalation anesthetic protocol that satisfied the selection criteria for the GRADE process. The panel decided to combine the recommendation about $\mathrm{CO}_{2} / \mathrm{O}_{2}$ anesthesia regardless of differences in application, doses, and flow rates. The GRADE summary of findings for changes in outcomes associated with $\mathrm{CO}_{2} /$ $\mathrm{O}_{2}$ anesthesia is presented in Table 4. The panel assessment of the quality of the body of work is presented in the evidence profile (Table 5). The outcomes with sufficient evidence were cortisol (within $60 \mathrm{~min}$, and between 1 and $24 \mathrm{~h}$ ) and $\beta$-endorphins (within $60 \mathrm{~min}$ ). The panel could not achieve a consensus about imprecision for the $\beta$-endorphin evidence (Table 3 ). The recommendation, rationale, and proposal for review are presented in Table 6.

Three relevant outcomes were available to assess the effect of $\mathrm{CO}_{2} / \mathrm{O}_{2}$ general anesthesia: cortisol up to $60 \mathrm{~min}$ post castration, cortisol between 1 and $24 \mathrm{~h}$, and $\beta$-endorphin up to $60 \mathrm{~min}$ post castration (Table 4) (Lauer et al., 1994; Kohler et al., 1998; Schonreiter et al., 2000; Muhlbauer et al., 2009). Compared with the control group, use of the $\mathrm{CO}_{2} / \mathrm{O}_{2}$ general anesthesia intervention was associated with a reduction in each outcome. Four to five studies that included a total of 115-225 animals were available for each outcome. However, fewer studies reported the results in a format that allowed a metaanalysis to be performed. Overall, the quality of the evidence for each outcome was rated at very low to moderate. Risk of bias, inconsistency, indirectness, and imprecision results are presented in Table 5.

The recommendation and the rationale for use of the intervention $\mathrm{CO}_{2} / \mathrm{O}_{2}$ general anesthesia are presented in Table 6. The overall quality of the evidence for the use of $\mathrm{CO}_{2} / \mathrm{O}_{2}$ general anesthesia was considered to be very low. Consideration of three outcomes contributed to this judgment (i.e. magnitude of the observed effect, importance of the observed effect, and the potential for biased results).

The use of general inhalation anesthesia has been proposed as a method to reduce pain manifestations associated with castration of piglets aged 1 through 28 days. There was a limited number of studies that 
Table 6. Recommendation against the use of $\mathrm{CO}_{2} / \mathrm{O}_{2}$ general anesthesia

Recommendation: the panel's current recommendation is a strong recommendation against the use of a $\mathrm{CO}_{2} / \mathrm{O}_{2}$ general anesthesia mixture for pain mitigation during castration of piglets 1-28 days of age.

We propose that this recommendation could be revisited in 3-5 years if new, high-quality, research is published that assesses critical outcomes, replicates the speed of on-farm castration, replicates the spectrum of piglet weights at castration in US production, and assesses adverse events.

\begin{tabular}{lll}
\hline Factor & Decision & Explanation \\
\hline Quality of & Very low & Few studies were available to assess the efficacy of this intervention; the
\end{tabular}

evidence

Balance of benefits and harms

Potential for harm outweighs the potential benefits

Values and preferences

Major variation in values and preferences present outcomes assessed did not enable the panel to understand the impact of the pain experience on the animals. If animals are properly anesthetized, the expectation was that pain was mitigated during the castration procedure. It is unclear if appropriate anesthesia levels can be consistently achieved on-farm. Further, it is not known if general anesthesia during castration results in no change, reduced, or increased pain manifestations $1-24 \mathrm{~h}$ after the procedure.

General anesthesia is a complex procedure, and clearly the potential exists for under- or overdosing that would result in either no effect or increased mortality. In a production setting with different ages and weights of piglets to process, it is currently unrealistic to expect producers to rapidly, consistently, and safely administer general anesthesia with existing tools. Further, the potential for harm to workers adds an additional concern about the safety of the on-farm use of general anesthetics for pain mitigation. These concerns were major drivers for the strength and direction of the recommendation provided by the panel.

The information about values and preferences was assessed based on what the panel members thought were perspectives held by consumers of pork and by citizens generally. There are large variations in how the consumers and citizens value pain mitigation but there is still little data to indicate what exactly these groups thought about the moral status of pain and the necessity of using certain pain mitigation strategies. In making this assessment, the results from voter initiatives were used as evidence of citizen values, whereas the observed low willingness to pay scores observed in the US markets provided dichotomous evidence of consumer valuations. No direct data about pain mitigation in piglets or consumer preferences was used. It was also noted that willingness to pay may be difficult to document in the US market, where there are few unique entry points for pork with differentiated production processes. This situation differs from egg production, where more direct market channels exist for differentiated products, such as cage-free eggs. Given the current difficulties with implementing general anesthesia on farm, it is unlikely that more consistency in values and preferences would change the panel's recommendation.

Resources The panel did not include a vote on the impact of resources; however, comment about the issues is warranted. Documentation that administration equipment is affordable, reproducible in effect, rapid, applicable to the production site, and safe for animals and workers would be required for this to be considered a practical intervention. Coupled with non-steroidal anti-inflammatory drugs application, general anesthesia may fit into a pain mitigation strategy for castration. measured cortisol response at $60 \mathrm{~min}$ and $24 \mathrm{~h}$, and $\beta$-endorphins at $60 \mathrm{~min}$ (Dzikamunhenga et al., 2014) (Table 4). The panel's strong recommendation against the use of $\mathrm{CO}_{2} / \mathrm{O}_{2}$ for pain mitigation during castration of 1- to 28-day-old piglets was partly based on this paucity of reviewable studies. There was also little evidence of pain mitigation after anesthesia recovery. Carbon dioxide can produce concentration- and flow rate-dependent pain and distress during the induction phase of anesthesia.
Carbonic acid produced in respiratory and ocular membranes stimulates feelings of breathlessness and direct stimulation of the ion channels in the amygdala (AVMA, 2013). The quality of information was graded as low to moderate for evaluation of post-anesthesia cortisol and $\beta$-endorphin levels. The risk:reward ratio was judged as poor because there were many barriers to successful anesthetic application in the field (i.e. a wide age-related range in body weight, the lack of standardized equipment 
Table 7. Summary of findings for nonsteroidal anti-inflammatory drug (NSAID) use during castration

NSAIDs for pain mitigation during castration of piglets $1-28$ of age

Population: Pain mitigation during castration of piglets 1-28 days of age.

Setting: Commercial swine production facilities

Intervention: NSAIDs

\begin{tabular}{|c|c|c|c|c|}
\hline \multirow[b]{2}{*}{ Outcomes } & Illustrative comparative risks* $(95 \% \mathrm{Cl})$ & \multirow{2}{*}{$\begin{array}{l}\text { No. of } \\
\text { participants } \\
\text { (studies) }\end{array}$} & \multirow{2}{*}{$\begin{array}{l}\text { No. of } \\
\text { participants } \\
\text { (studies) }\end{array}$} & \multirow{2}{*}{$\begin{array}{l}\text { Quality of } \\
\text { the evidence } \\
(\text { GRADE)** }\end{array}$} \\
\hline & Corresponding risk & & & \\
\hline & NSAIDs & & & \\
\hline Cortisol, $60 \mathrm{~min}$ & $\begin{array}{l}\text { The mean cortisol within } 60 \text { min of } \\
\text { castration in the intervention groups } \\
\text { was } 93.59 \text { lower (138.44-48.74 lower) }\end{array}$ & $634(14)^{1-6}$ & & $\begin{array}{l}\oplus \oplus \oplus \oplus \\
\text { High }^{7}\end{array}$ \\
\hline Cortisol, $24 \mathrm{~h}$ & $\begin{array}{l}\text { The mean cortisol } 1-24 \mathrm{~h} \text { after } \\
\text { castration in the intervention groups } \\
\text { was } 39.17 \text { lower }(51.87-26.47 \text { lower) }\end{array}$ & $441(9)^{1,2,4-6}$ & $295\left(7^{1,3,4}\right)$ & $\begin{array}{l}\oplus \oplus \oplus \ominus \\
\text { Moderate }^{8}\end{array}$ \\
\hline $\begin{array}{l}\text { Vocalization }(\mathrm{dB}) \text {, } \\
60 \text { min }\end{array}$ & $\begin{array}{l}\text { The mean vocalization }(\mathrm{dB}) \text { within } \\
60 \text { min of castration in the intervention groups } \\
\text { was } 47.4 \text { higher ( } 54.03 \text { lower to } 148.82 \text { higher) }\end{array}$ & $357(5)^{1-3,5}$ & $342\left(2^{3}\right)$ & $\begin{array}{l}\oplus \oplus \oplus \oplus \\
\text { High }^{7}\end{array}$ \\
\hline $\begin{array}{l}\text { Pain-like } \\
\text { behaviours } 24 \mathrm{~h}\end{array}$ & $\begin{array}{l}\text { The mean pain-like behaviours } 1-24 \mathrm{~h} \text { after } \\
\text { castration in the intervention groups was } \\
0.30 \text { standard deviations higher } \\
(0 \text { to } 0.59 \text { higher) }\end{array}$ & $280(5)^{1-3,5}$ & $180(3)^{1}$ & $\begin{array}{l}\oplus \oplus \oplus \ominus \\
\text { High/moderate }\end{array}$ \\
\hline
\end{tabular}

"The basis for the assumed risk (e.g. the median control group risk across studies) is provided in the footnotes. The corresponding risk (and its 95\% confidence interval) is based on the assumed risk in the comparison group and the relative effect of the intervention (and its 95\% Cl).

$\mathrm{Cl}$ : Confidence interval.

"GRADE Working Group grades of evidence:

High quality: further research is very unlikely to change our confidence in the estimate of effect.

Moderate quality: further research is likely to have an important impact on our confidence in the estimate of effect and may change the estimate.

Low quality: further research is very likely to have an important impact on our confidence in the estimate of effect and is likely to change the estimate.

Very low quality: we are very uncertain about the estimate.

${ }^{1}$ Randomized, blinded, and blocked.

${ }^{2}$ Randomized, blinded, and unblocked.

${ }^{3}$ Randomized, not blinded, and blocked.

${ }^{4}$ Randomized, not blinded, and not blocked.

${ }^{5}$ Nonrandomized, not blinded, and blocked.

${ }^{6}$ Nonrandomized, not blinded, and not blocked.

${ }^{7}$ No explanation was provided.

$8 \sim 50 \%$ failed to include information about controlling for important confounders and blinding.

and protocols, and variable applicator administration skills). The risk of mortality from an anesthetic overdose and the high likelihood that the intervention would be ineffective also contributed to the low rank. The likelihood that the negative risk:reward rating could be improved by additional research was judged to be low.

\subsection{Intervention: non-steroidal anti-inflammatory drugs}

The panel's current position is a weak recommendation for the use of NSAIDs for pain mitigation during castration of 1- to 28-day-old piglets.

\subsubsection{Discussion of recommendation for non-steroidal anti-inflammatory drugs}

Several NSAIDs were evaluated (e.g. meloxicam, flunixin meglumine, and carprofen). Cortisol concentrations (under $60 \mathrm{~min}$, and between 1 and $24 \mathrm{~h}$ ), vocalization $(\mathrm{dB})$, and pain-like behaviors between 1 and $24 \mathrm{~h}$ were the outcomes that were available for voting (Table 7) (Zols et al., 2006; Rebecca et al., 2009; Courboulay et al., 2010; Sutherland et al., 2010, 2012; Hansson et al., 2011; Kluivers-Poodt et al., 2012; Reiner et al., 2012; Schwab et al., 2012; Tenbergen, 2012; Wavreille et al., 2012). The results for the panel assessment of the quality of the body of work are reported in the evidence profile (Table 8). The recommendation, rationale, and proposal for review of the NSAID recommendations are described in Table 9.

Indirectness was not included in the voting process, because there was no evidence of serious indirectness. The very narrow target population, and the votes of 'low' applied across all outcomes and all interventions. A consensus about imprecision was not achieved for the vocalization measure (Table 3 ). 
Table 8. Evidence profiles for non-steroidal anti-inflammatory drugs during castration

\begin{tabular}{|c|c|c|c|c|c|c|c|c|c|c|}
\hline \multicolumn{7}{|c|}{ Quality assessment } & \multicolumn{2}{|c|}{ Number of piglets } & \multirow[b]{2}{*}{ Quality } & \multirow[b]{2}{*}{ Importance } \\
\hline $\begin{array}{l}\text { No of } \\
\text { studies }\end{array}$ & Design & Risk of bias & Inconsistency & Indirectness & Imprecision & $\begin{array}{l}\text { Other } \\
\text { considerations }\end{array}$ & Intervention & Control & & \\
\hline \multicolumn{11}{|c|}{ Cortisol, $60 \mathrm{~min}$} \\
\hline 11 & $\begin{array}{l}\text { Randomized } \\
\text { trials }^{1-12}\end{array}$ & $\begin{array}{l}\text { No serious } \\
\text { risk of bias }\end{array}$ & $\begin{array}{l}\text { No serious } \\
\text { inconsistency }\end{array}$ & $\begin{array}{l}\text { No serious } \\
\text { indirectness }\end{array}$ & $\begin{array}{l}\text { No serious } \\
\text { imprecision }\end{array}$ & None & 233 & 255 & $\begin{array}{l}\oplus \oplus \oplus \oplus \\
\text { High }\end{array}$ & Important \\
\hline \multicolumn{11}{|c|}{ Cortisol, $24 \mathrm{~h}$} \\
\hline 7 & $\begin{array}{l}\text { Randomized } \\
\text { trials }{ }^{1,2,7,9-12}\end{array}$ & Serious $^{13}$ & $\begin{array}{l}\text { No serious } \\
\text { inconsistency }\end{array}$ & $\begin{array}{l}\text { No serious } \\
\text { indirectness }\end{array}$ & $\begin{array}{l}\text { No serious } \\
\text { imprecision }\end{array}$ & None & 138 & 157 & $\begin{array}{l}\oplus \oplus \oplus \ominus \\
\text { Moderate }\end{array}$ & Important \\
\hline \multicolumn{11}{|c|}{ Vocalization $(\mathrm{dB}), 60 \mathrm{~min}$} \\
\hline 2 & $\begin{array}{l}\text { Randomized } \\
\text { trials }\end{array}$ & $\begin{array}{l}\text { No serious } \\
\text { risk of bias }\end{array}$ & $\begin{array}{l}\text { No serious } \\
\text { inconsistency }\end{array}$ & $\begin{array}{l}\text { No serious } \\
\text { indirectness }\end{array}$ & $\begin{array}{l}\text { No serious } \\
\text { imprecision }\end{array}$ & None & 171 & 171 & $\begin{array}{l}\oplus \oplus \oplus \oplus \\
\text { High }\end{array}$ & Not important \\
\hline \multicolumn{11}{|c|}{ Pain-like behaviors, $24 \mathrm{~h}$} \\
\hline 3 & $\begin{array}{l}\text { Randomized } \\
\text { trials }^{1-3}\end{array}$ & $\begin{array}{l}\text { No serious } \\
\text { risk of bias }\end{array}$ & $\begin{array}{l}\text { No serious } \\
\text { inconsistency }\end{array}$ & $\begin{array}{l}\text { No serious } \\
\text { indirectness }\end{array}$ & Serious $^{14}$ & None & 90 & 90 & $\begin{array}{l}\oplus \oplus \oplus \ominus \\
\text { Moderate/High }\end{array}$ & Not rated \\
\hline
\end{tabular}

${ }^{1}$ Randomized, blinded, and blocked.

${ }^{2}$ Randomized, blinded, and blocked.

${ }^{3}$ Randomized, blinded, and blocked.

${ }^{4}$ Randomized, blinded, and blocked.

${ }^{5}$ Randomized, blinded, and blocked.

${ }^{6}$ Randomized, blinded, and not blocked

${ }^{7}$ Randomized, not blinded, and blocked.

${ }^{8}$ Randomized, not blinded, and blocked.

${ }^{9}$ Randomized, not blinded, and not blocked.

${ }^{10}$ Randomized, not blinded, and not blocked

${ }^{11}$ Randomized, not blinded, and not blocked.

${ }^{12}$ Randomized, not blinded, and not blocked.

${ }^{13}$ Approximately $50 \%$ of the studies failed to include information about controlling for important confounders and blinding.

${ }^{14} \mathrm{No}$ consensus was reached, so it was recorded as high/moderate. 
Table 9. Recommendation for use of non-steroidal anti-inflammatory drugs (NSAIDs) during castration

Recommendation: The panel's current recommendation is a weak recommendation for the use of NSAIDs for pain mitigation during castration of piglets $1-28$ days of age.

We propose that this recommendation about the use of NSAIDs as an approach to castration could be revisited in 1-2 years if new products become available on the US market, and if outcomes critical for long-term pain mitigation are included in the studies

\begin{tabular}{lll}
\hline Factor & Decision & Explanation \\
\hline $\begin{array}{l}\text { Quality of } \\
\text { evidence }\end{array}$ & Low & $\begin{array}{l}\text { There is an absence of critical outcomes measured for this intervention. This is an } \\
\text { intervention designed to mitigate pain } 1-24 \mathrm{~h} \text { after the procedure. The } \\
\text { recommendation means the panel placed high value on the cortisol results for this } \\
\text { time frame. It was recognized by the panel that cortisol is not a specific indicator of } \\
\text { pain, and validated pain assessment measures are needed to more fully assess the } \\
\text { benefits of NSAID administration to alleviate the pain associated with castration. } \\
\text { The vocalization results indicate that NSAIDs do not mitigate the acute pain } \\
\text { associated with the procedure. The vocalization results were not unexpected, given } \\
\text { the mechanism of action of these products but provided another reason that the } \\
\text { recommendation was weak rather than strong for these products }\end{array}$
\end{tabular}

Balance of The potential for benefit benefits and outweighs the potential harms harms

Values and preferences Major variations in values and preferences present
The panel felt that the likely benefits outweighed the harms for NSAIDs. Unlike general anesthesia, the potential for overdose is minimal. Current NSAID products provide a reasonable margin of product safety for published dose regimens. Additionally, the products are routinely applied via commonly used routes of administration in commercial swine production facilities. There is a limited expectation of benefit for incisional pain with benefits limited to the reduction of inflammatory pain after the procedure

The information about values and preferences was assessed based on what the panel members thought were perspectives held by consumers of pork and by citizens generally. There are large variations in how the consumers and citizens value pain mitigation but there is still little data to indicate what exactly these groups thought about the moral status of pain and the necessity of using certain pain mitigation strategies. In making this assessment, the results from voter initiatives were used as evidence of citizen values, whereas the observed low willingness to pay scores observed in the US and overseas markets provided dichotomous evidence of consumer valuations. No direct data about pain mitigation in piglets or consumer preferences was used. It was also noted that willingness to pay may be difficult to document in the US market, where there are few unique entry points for pork with differentiated production processes. This situation differs from egg production, where more direct market channels exist for differentiated products, such as cage-free eggs, became available that better clarified the preferences of pork consumers and citizen this would potential strengthen the panel's recommendation. If data became available that clarified the preferences of pork consumers and citizens, the panel's recommendation could be strengthened

Resources

Currently, the absence of an FDA-registered product for pain mitigation is a major barrier that must be resolved. The primary impediment to regulatory approval for pain indications is the absence of validated methods for pain assessment in swine. Similarly, several of the products under consideration are considered prescription drugs. Such a designation makes their widespread use in production settings more difficult and expensive to manage
Meloxicam was the NSAID most commonly studied for pain mitigation during castration. Given the mechanism of action of NSAIDs, this class of drugs is not likely to mitigate incisional pain transmission via nerves, because they generally transfer stimuli as electric pulses (Coetzee, 2013b). These rapid transmissions begin almost immediately after castration. NSAIDs are more likely to affect inflammatory pain stimuli that are transmitted as a consequence of the production of cytokines and prostaglandins when cell walls are damaged and metabolized
(Coetzee, 2013a). NSAIDs interfere with the enzymes involved in the synthesis and metabolism of prostaglandins, and change the ratios of cytokine concentrations (Ochroch et al., 2003; Fraccaro et al., 2013). Specific cytokines vary in the degree of pain produced, so overall pain perception is affected by the cytokine ratio. The NSAIDs findings were consistent with this understanding (Table 11). Mean cortisol levels were lower at $60 \mathrm{~min}$ and at $24 \mathrm{~h}$ after castration, but vocalization energy was higher during castration. Greater frequency of 
Table 10. Summary of findings for local anesthesia during castration

Local anesthesia for pain mitigation during castration of piglets 1-28 days of age.

Population: Pain mitigation during castration of piglets 1-28 days of age

Setting: Commercial swine production facilities

Intervention: Local anesthesia

\begin{tabular}{|c|c|c|c|c|}
\hline \multirow[b]{2}{*}{ Outcomes } & Illustrative comparative risks* (95\% Cl) & \multirow{2}{*}{$\begin{array}{l}\text { No. of } \\
\text { participants } \\
\text { (studies) }\end{array}$} & \multirow{2}{*}{$\begin{array}{l}\text { No. of participants } \\
\text { in the meta-analysis } \\
\text { (studies) }\end{array}$} & \multirow[b]{2}{*}{$\begin{array}{l}\text { Quality of the } \\
\text { evidence (GRADE)* }\end{array}$} \\
\hline & $\begin{array}{l}\text { Corresponding risk } \\
\text { Local anesthesia }\end{array}$ & & & \\
\hline Energy $60 \mathrm{~min}$ & $\begin{array}{l}\text { The mean vocalization energy }(\mathrm{dB}) \\
\text { within } 60 \text { min of castration was } \\
8.8 \text { lower for the intervention groups } \\
\text { (10.86-6.74 lower) }\end{array}$ & $342(4)^{1,2}$ & $342(2)^{1}$ & $\oplus \oplus \oplus \ominus$ Moderate \\
\hline
\end{tabular}

"The basis for the assumed risk (e.g. the median control group risk across studies) is provided in the footnotes. The corresponding risk (with 95\% confidence interval) is based on the assumed risk in the comparison group and the relative effect of the intervention (with $95 \% \mathrm{Cl}$ ).

$\mathrm{Cl}$ : Confidence interval.

*** GRADE Working Group grades of evidence

High quality: further research is very unlikely to change our confidence in the estimate of effect.

Moderate quality: further research is likely to have an important impact on our confidence in the estimate of effect and may change the estimate.

Low quality: further research is very likely to have an important impact on our confidence in the estimate of effect and is likely to change the estimate.

Very low quality: we are very uncertain about the estimate.

${ }^{1}$ Randomized, not blinded, and blocked.

${ }^{2}$ Not randomized, not blinded, and blocked.

pain-associated behaviors were observed in the intervention group (at $24 \mathrm{~h}$ ). A delay in the start of cytokinemediated pain is expected, but the relative rate at which each subsides is unknown. A pain-associated behavior observed at $24 \mathrm{~h}$ may not represent a specific cytokinerelated response, or be an accurate indicator of NSAID activity.

The quality of the NSAID studies was rated as high, but the panel concluded that an insufficient number of outcomes had been evaluated for this intervention. Most of the panel decisions relied primarily on cortisol as an outcome. Among the 14 outcomes characterized as important, only the outcomes cortisol and vocalisation were evaluated. Consequently, the overall quality of the evidence for this intervention was judged to be low. Additional research and assessment of NSAIDs for critical outcomes would likely strengthen the evidence required to formulate recommendations. For physiological impact, the potential for benefits was judged to outweigh the potential for harms. However, from a resource perspective the lack of an FDA-approved analgesic compound for use in food animals was considered to be a major barrier to implementation.

\subsection{Intervention: local anesthesia - lidocaine}

The panel's current recommendation is a weak recommendation against the use of lidocaine as a pain mitigation strategy during castration of piglets aged 1-28 days.

\subsubsection{Discussion of recommendation for lidocaine}

Lidocaine was the only local anesthesia pain mitigation strategy that was identified, and vocalization (dB) was the only outcome available for voting (Tables 3 and 10) (White et al., 1995; Horn et al., 1999; Marx et al., 2003; Rittershaus et al., 2009; Hansson et al., 2011; Kluivers-Poodt et al., 2012; Temple et al., 2012). The voting process was not used for indirectness because no serious indirectness of evidence was found. The consensus was that there was a low risk of bias among the studies that reported this outcome and that the evidence demonstrated low inconsistency. The panelists agreed (94\%) that the overall quality of the body of work was very low (Table 11). Table 12 presents the recommendation, rationale, and proposal for review of the lidocaine recommendations.

The panel considered the use of lidocaine for pain mitigation during castration of piglets 1-28 days of age. Cortisol levels $60 \mathrm{~min}$ after surgery were used as evidence of efficacy of pain relief. Only two studies measured effects, but both found that cortisol levels were lower in treatment pigs. The panel assigned a score of moderate quality to this research (Table 12). Vocalization scores indicated that pain during castration was not mitigated by lidocaine anesthesia. The quality of evidence to support this intervention was judged to be very low. A risk:reward ratio could not be determined from the available evidence. However, a minimal number of rewards were reported, so the likelihood of a positive ratio was low. Although there were a small number of studies available for review, their results were graded 
as moderate. Therefore, the panel concluded that this intervention should be studied further (i.e. measurement of a range of critical outcomes and assessment of the potential for adverse events). The results of these new studies combined with older studies should be reevaluated in several years to determine if the evidence base for local anesthesia has changed and different conclusions would be reached.

\section{Declarations of interests}

Dr Anthony is the ethics advisor for American Veterinary Medicine Association's Animal Welfare Committee and currently receives funding from USDA.

Dr Bergamasco has been a consultant for Hormel Foods Corporation, co-investigator in funding from NPB, and has received funding from USDA-CSREES, Animal Protection (Animal Well-being), NRI Grant no. 200965120-05729.

Dr Coetzee has been a consultant for Intervet-Schering Plough Animal Health (Now Merck), Boehringer-Ingelheim Vetmedica, Zoetis Animal Health and Norbrook Laboratories Ltd. He has also addressed the Staff College at the US Food and Drug Administration (FDA) Center for Veterinary Medicine (CVM) and has received funding from USDA-CSREES, Animal Protection (Animal Wellbeing), NRI Grant nos 2008-35204-19238, 2009-6512005729, 2012-67021-19363 and 2011-67021-30369).

Dr Dzikamunhenga was supported as a postdoctoral fellowship funded by the National Pork Board.

Ms Gould was partially supported by the National Pork Board.

Dr Johnson serves on the Animal Welfare Committee for the NPB, and the Animal Well-being committee for IPPA, and receives complimentary travel and lodging to attend meetings. She currently consults for Bob Evans, Elanco, McDonalds and Murphy-Brown, LLC. In the past she has consulted for Kroger's. Funding has been received through the following pharmacology agencies Boehringer-Ingelheim Vetmedica, Elanco and Pfizer. Dr Johnson has received funding for welfare related research from NPB. Dr Johnson has pain related research has been funded by Agriculture and Food Research Initiative competitive grants from the USDA National Institute of Food and Agriculture (Grant no. 2011-6702130369).

Dr Locke Karriker has been a consultant for Boehringer Ingelheim Vetmedica and Bayer Animal Health. He currently has active research funding from the National Pork Board, the Iowa Pork Producers Association, the USDA Higher Education Challenge Competitive Grants Program, and Boehringer Ingelheim Vetmedica. He is the Director of the Swine Medicine Education Center at Iowa State University. Dr Karriker has pain related research 
Table 12. Use of lidocaine during castration

Recommendation: The panel's current recommendation is a weak recommendation against the use of lidocaine for pain mitigation during castration of piglets 1-28 days of age.

We propose that this recommendation about the use of local anesthetic as an approach to pain mitigation during castration could be revisited in 1-2 years if new high-quality studies that assessed critical outcomes, replicated the onfarm speed of castration, approximated the spectrum of piglet weights to be castrated in the US production, and assessed possible adverse events are published, and if information required for appropriate off-label use or registration for use to mitigate pain in piglets becomes available

\begin{tabular}{lll}
\hline Factor & Decision & Explanation \\
\hline Quality of & Very low & Lidocaine is an intervention designed to mitigate pain in the short term, that
\end{tabular}

evidence

Balance of benefits and harms
Uncertainty that the potential benefits were greater than the harms
Values and preferences
Major variation in values and preferences is, $1-2 \mathrm{~h}$ after the procedure. There was an absence of information about the a priori identified critical outcomes for this intervention. For this intervention, we would expect that only incisional pain associated with the procedure would be mitigated. Two studies did indicate that administration of lidocaine did reduce vocalization, as measured by call energy. However, there was debate among the panel about the value of this outcome; therefore, the evidence base was considered very low

The uncertainty expressed here about the balance of benefits and harms by the panel was related to a failure to document the extent of benefits. The benefit to the piglet is that, provided the extra application steps necessary to utilize this product where utilized, local anesthetic would mitigate pain in the short term. However, for two reasons, the panel proposed that those benefits may not be as great as expected. First, in the US production system, there is reluctance and practical difficulties to taking the extra steps to administer lidocaine before the procedure. If these steps are not taken, little real benefit for the piglet is realised. Further, based on the mechanism of action rather than on empirical studies in piglets, we would not expect that inflammatory pain associated with castration to be mitigated by lidocaine. These uncertainties weakened the recommendations. Possible harms to the piglet were thought to be minimal, as lidocaine is widely used in human and animal health, and has a reasonable margin of product safety; therefore, the harms that would occur are minimal. It is also theoretically possible that lidocaine could adversely affect wound healing

The information about values and preferences was assessed based on what the Panel thought were perspectives held by consumers of pork and by citizens generally. There are large variations in how the consumers and citizens value pain mitigation but there is still little data to indicate what exactly these groups thought about the moral status of pain and the necessity of using certain pain mitigation strategies. In making this assessment, the results from voter initiatives were used as evidence of citizen values, whereas the observed low willingness to pay scores observed in the US markets provided dichotomous evidence of consumer valuations. No direct data about pain mitigation in piglets or consumer preferences was used. It was also noted that willingness to pay may be difficult to document in the US market, where there are few unique entry points for pork with differentiated production processes. This situation differs from egg production, where more direct market channels exist for differentiated products, such as cage-free eggs

As with non-steroidal anti-inflammatory drugs, the absence of FDAregistered products for local anesthesia to reduce pain in swine is a major barrier that must be resolved if local anesthetic products are to be adopted. Lidocaine is a prescription drug requiring regulation at point of use to address untoward effects from its use. This is not a trivial barrier to adoption, because extra label use of products in the USA falls under the jurisdiction of AMDUCA. Among the processes required by AMDUCA, veterinarians must provide producers with withdrawal times for meat production. Such information is difficult to obtain, as methods of determining meat withdrawals are not harmonized across countries, and withholding times used in swine production elsewhere cannot be guaranteed to meet FDA requirements. For producers, extra-label drug use requires the maintenance of records that indicate the animals treated and the dose. Such a designation makes the widespread use of lidocaine in US production settings difficult and expensive to manage for the producer and legally difficult for veterinarians. The failure to document great benefit combined with resource issues led to a weak recommendation against the use of local anesthetic 
has been funded by Agriculture and Food Research Initiative competitive grants from the USDA National Institute of Food and Agriculture (Grant no. 2011-6702130369).

Dr Marchant-Forde has received research funding from, and been a research grant reviewer for NPB. Funding has been received through Elanco for projects unrelated to pain interventions. As a Federal Government employee, he has had no financial compensation for consulting activities from any commercial company.

Dr Martineau has received research funding from Bayer, Boehringer-Ingelheim, MSD, Novartis, VIRBAC, Zoetis. None of these researches were related on drugs related to pain. He is also regularly consultant for major swine Coops in France as well as 'Institut Technique du Porc' similar to NPB.

Dr McKean serves on the NPB Animal Welfare Committee and has served on the IPPA Swine Health and Welfare Committee and as such received complimentary travel and lodging to attend meetings. McKean has received research grants from the NPB. He does not solicit animal welfare funding or consultation arrangements. Dr McKean has received funding for food safety research from NPB and the current project related to animal welfare.

Dr Millman current serves on the Animal Well-being Committee for Iowa Pork Producers Association, and advises McDonalds Corporation, Humane Farm Animal Care and HyLine International (poultry) on animal welfare issues. Her pain related research has been funded by Agriculture and Food Research Initiative competitive grants from the USDA National Institute of Food and Agriculture (Grant nos 2012-67021-19363 and 2011-6702130369), Natural Sciences and Engineering Research Council of Canada, Canadian Foundation for Innovation, National Pork Board, Iowa Pork Producers, Ontario Pork, Boehringer-Ingelheim Vetmedica (bovine only), Novartis Animal Health (bovine), Intervet-Schering Plough Animal Health (bovine), Pfizer Animal Health (bovine), Merck-Merial (bovine). She has received complimentary travel and lodging to attend meetings from BoehringerIngelheim Vetmedica, Inc.

Ms Sherrie Niekamp is employed by the National Pork Board as the Director of Swine Welfare. The national Pork Board has responsibility for Checkoff-funded research, promotion and consumer information projects and for communicating with pork producers and the public. Through a legislative national Pork Checkoff, pork producers invest $\$ 0.40$ for each $\$ 100$ value of hogs sold. Importers of pork products contribute a like amount, based on a formula. The Pork Checkoff funds international, national and state programs in advertising and promotion, consumer information, and research in production improvement, swine health, pork safety, public health, animal welfare and environmental management.

Dr O'Connor serves on the food safety committee for the NPB and receives complimentary travel and lodging to attend meetings. Dr O'Connor has received funding for food safety research from NPB and the current project related to animal welfare. Dr O'Connor has been funded for projects by Pfizer Animal Health unrelated to pain interventions or swine welfare. Dr O'Connor teaches clinical trial design for swine producers for BoehringerIngelheim Vetmedica. Dr O'Connor is a collaborator on a pain-related research funded by Agriculture and Food Research Initiative competitive grants from the USDA National Institute of Food and Agriculture (Grant no. 2012-67021-19363)

Dr Pajor has received research funding from the NPB and USDA-ARS. He currently serves as an advisor to the Animal Welfare Committee of the National Pork Board as well as other organizations (McDonad's, Safeway, Certified Humane). Although he has received complimentary travel and lodging to attend meetings, he receives no other financial compensation for consulting activities from any commercial company.

Dr Rutherford has received funding from Zoetis for research on pain in pigs.

Dr Sprague has received complimentary travel and lodging to attend meetings from BoehringerIngelheim Vetmedica, Inc., Zoetis and Novartis Animal Health.

Dr Sutherland has received funding from the National Pork Board for research on pain in pigs.

Dr Eberhard von Borell has received past complimentary travel funds for attending meetings from Boehringer-Ingelheim and funding for research money from Zoetis. Research money was not related to pain study.

\section{Funding}

This project was funded by the National Pork Board (NPB) (Grant no. 12-186).

\section{References}

Andrews J, Guyatt G, Oxman AD, Alderson P, Dahm P, FalckYtter Y, Nasser M, Meerpohl J, Post PN, Kunz R, Brozek J, Vist G, Rind D, Akl EA and Schunemann HJ (2013a). GRADE guidelines: 14. Going from evidence to recommendations: the significance and presentation of recommendations. Journal of Clinical Epidemiology 66: 719-725.

Andrews JC, Schunemann HJ, Oxman AD, Pottie K, Meerpohl JJ, Coello PA, Rind D, Montori VM, Brito JP, Norris S, Elbarbary M, Post P, Nasser M, Shukla V, Jaeschke R, Brozek J, Djulbegovic B and Guyatt G (2013b). GRADE guidelines: 15. Going from evidence to recommendation-determinants of a recommendation's direction and strength. Journal of Clinical Epidemiology 66: 726-735.

Appleby MC (2005). The relationship between food prices and animal welfare. Journal of Animal Science 83: E9-E12.

Aubert A (1999). Sickness and behaviour in animals: a motivational perspective. Neuroscience and Biobehavioral Reviews 23: 1029-1036. 
AVMA (2013). AVMA Guidelines for the Euthanasia of Animals: 2013 edition. 978-1-882691-21-0.

Balshem H, Helfand M, Schunemann HJ, Oxman AD, Kunz R, Brozek J, Vist GE, Falck-Ytter Y, Meerpohl J, Norris S and Guyatt GH (2011). GRADE guidelines: 3. Rating the quality of evidence. Journal of Clinical Epidemiology 64: 401-406.

Botonaki A, Polymeros K, Tsakiridou E and Mattas K (2006). The role of food quality certification on consumers' food choices. British Food Journal 108: 77-90.

Brunetti M, Shemilt I, Pregno S, Vale L, Oxman AD, Lord J, Sisk J, Ruiz F, Hill S, Guyatt GH, Jaeschke R, Helfand M, Harbour R, Davoli M, Amato L, Liberati A and Schunemann HJ (2013). GRADE guidelines: 10. Considering resource use and rating the quality of economic evidence. Journal of Clinical Epidemiology 66: 140-150.

Coetzee JF (2013a). Assessment and management of pain associated with castration in cattle. Veterinary Clinics of North America-Food Animal Practice 29: 75-101.

Coetzee JF (2013b). A review of analgesic compounds used in food animals in the United States. Veterinary Clinics of North America-Food Animal Practice 29: 11-28.

Courboulay V, Hemonic A, Gadonna M and Prunier A (2010). Effect of local anesthesia or anti-inflammatory treatment on pain associated with piglet castration and on labour demand Castration avec anesthesie locale ou traitement anti-inflammatoire: quel impact sur la douleur des porcelets et quelles consequences sur le travail en elevage? Journess de la recherche Porcine en France 42: 27-34.

Dzikamunhenga RS, Anthony R, Coetzee J, Gould S, Johnson A, Karriker L, McKean JD, Millman ST, Niekamp SR and O'Connor AM (2014). Pain management in the neonatal piglet during routine management procedures. Part 1: a systematic review of randomized and non-randomized intervention studies. Animal Health Research Reviews, in press.

Food and Agricultural Organization of the United Nations (FAO) (2009). The State of Food and Agriculture 2009: Towards a Responsible Livestock Future. Rome.

Fraccaro E, Coetzee JF, Odore R, Edwards-Callaway LN, KuKanich B, Badino P, Bertolotti L, Glynn H, Dockweiler J, Allen K and Bergamasco L (2013). A study to compare circulating flunixin, meloxicam and gabapentin concentrations with prostaglandin E-2 levels in calves undergoing dehorning. Research in Veterinary Science 95: 204-211.

Fretheim A, Schunemann HJ and Oxman AD (2006a). Improving the use of research evidence in guideline development: 3 . Group composition and consultation process. Health Research Policy and Systems 4: 15.

Fretheim A, Schunemann HJ and Oxman AD (2006b). Improving the use of research evidence in guideline development: 5. Group processes. Health Research Policy and Systems 4: 17 .

Gottschalk A and Smith DS (2001). New concepts in acute pain therapy: preemptive analgesia. American Family Physician 63: 1979-1984.

Guyatt G, Oxman AD, Akl EA, Kunz R, Vist G, Brozek J, Norris S, Falck-Ytter Y, Glasziou P, DeBeer H, Jaeschke R, Rind D, Meerpohl J, Dahm P and Schunemann HJ (2011a). GRADE guidelines: 1. Introduction-GRADE evidence profiles and summary of findings tables. Journal of Clinical Epidemiology 64: 383-394.

Guyatt G, Oxman AD, Kunz R, Brozek J, Alonso-Coello P, Rind D, Devereaux P, Montori VM, Freyschuss B, Vist G, Jaeschke R, Williams Jr JW, Murad MH, Sinclair D, FalckYtter Y, Meerpohl J, Whittington C, Thorlund K, Andrews J and Schunemann HJ (2011b). GRADE guidelines 6. Rating the quality of evidence-imprecision. Journal of Clinical Epidemiology 64: 1283-1293.
Guyatt G, Oxman AD, Sultan S, Brozek J, Glasziou P, AlonsoCoello P, Atkins D, Kunz R, Montori V, Jaeschke R, Rind D, Dahm P, Akl EA, Meerpohl J, Vist G, Berliner E, Norris S, Falck-Ytter Y and Schunemann HJ (2012). GRADE guidelines 11-making an overall rating of confidence in effect estimates for a single outcome and for all outcomes. Journal of Clinical Epidemiology 62(2): 151-157.

Guyatt GH, Oxman AD, Kunz R, Atkins D, Brozek J, Vist G, Alderson P, Glasziou P, Falck-Ytter Y and Schunemann HJ (2011c). GRADE guidelines: 2. Framing the question and deciding on important outcomes. Journal of Clinical Epidemiology 64: 395-400.

Guyatt GH, Oxman AD, Kunz R, Woodcock J, Brozek J, Helfand M, Alonso-Coello P, Falck-Ytter Y, Jaeschke R, Vist G, Akl EA, Post PN, Norris S, Meerpohl J, Shukla VK, Nasser M and Schunemann HJ (2011d). GRADE guidelines: 8. Rating the quality of evidence-indirectness. Journal of Clinical Epidemiology 64: 1303-1310.

Guyatt GH, Oxman AD, Kunz R, Woodcock J, Brozek J, Helfand M, Alonso-Coello P, Glasziou P, Jaeschke R, Akl EA, Norris S, Vist G, Dahm P, Shukla VK, Higgins J, FalckYtter Y and Schunemann HJ (2011e). GRADE guidelines: 7. Rating the quality of evidence-inconsistency. Journal of Clinical Epidemiology 64: 1294-1302.

Guyatt GH, Oxman AD, Montori V, Vist G, Kunz R, Brozek J, Alonso-Coello P, Djulbegovic B, Atkins D, Falck-Ytter Y, Williams JW, Jr., Meerpohl J, Norris SL, Akl EA and Schunemann HJ (2011f). GRADE guidelines: 5. Rating the quality of evidence-publication bias. Journal of Clinical Epidemiology 64: 1277-1288.

Guyatt GH, Oxman AD, Schunemann HJ, Tugwell P and Knottnerus A (2011g). GRADE guidelines: a new series of articles in the Journal of Clinical Epidemiology. Journal of Clinical Epidemiology 64: 380-382.

Guyatt GH, Oxman AD, Sultan S, Glasziou P, Akl EA, AlonsoCoello P, Atkins D, Kunz R, Brozek J, Montori V, Jaeschke R, Rind D, Dahm P, Meerpohl J, Vist G, Berliner E, Norris S, Falck-Ytter Y, Murad MH, Schunemann $\mathrm{HJ}$ and Group GW (2011h). GRADE guidelines: 9. Rating up the quality of evidence. Journal of Clinical Epidemiology 64: 1311-1316.

Guyatt GH, Oxman AD, Santesso N, Helfand M, Vist G, Kunz R, Brozek J, Norris S, Meerpohl J, Djulbegovic B, AlonsoCoello P, Post PN, Busse JW, Glasziou P, Christensen R and Schunemann HJ (2013a). GRADE guidelines: 12. Preparing summary of findings tables-binary outcomes. Journal of Clinical Epidemiology 66: 158-172.

Guyatt GH, Oxman AD and Schunemann HJ (2013b). GRADE guidelines-an introduction to the 10th-13th articles in the series. Journal of Clinical Epidemiology $\mathbf{6 6}$ : 121-123.

Guyatt GH, Thorlund K, Oxman AD, Walter SD, Patrick D, Furukawa TA, Johnston BC, Karanicolas P, Akl EA, Vist G, Kunz R, Brozek J, Kupper LL, Martin SL, Meerpohl JJ, Alonso-Coello $\mathrm{P}$, Christensen $\mathrm{R}$ and Schunemann $\mathrm{HJ}$ (2013c). GRADE guidelines: 13. Preparing summary of findings tables and evidence profiles-continuous outcomes. Journal of Clinical Epidemiology 66: 173-183.

Hansson M, Lundeheim N, Nyman G and Johansson G (2011). Effect of local anaesthesia and/or analgesia on pain responses induced by piglet castration. Acta Veterinaria Scandinavica 53: 43.

Horn T, Marx G and von Borell E (1999). Behaviour of piglets during castration with and without a local anaesthesia. Deutsche Tierarztliche Wochenschrift 106: 271-274.

Author A (2008) GRADEpro. [Computer program]. Version 3.2 for Windows. Jan Brozek, Andrew Oxman, Holger Schünemann, 2008. 
Kissin I (2000). Preemptive analgesia. Anesthesiology 93: $1138-1143$.

Kluivers-Poodt M, Houx BB, Robben SRM, Koop G, Lambooij E and Hellebrekers LJ (2012). Effects of a local anaesthetic and NSAID in castration of piglets, on the acute pain responses, growth and mortality. Animal 6: 14691475.

Kohler I, Blum J, Schatzmann U, Moens Y and Busato A (1998). Inhalation anaesthesia for the castration of piglets: $\mathrm{CO}_{2}$ compared to halothane. Zentralblatt für Veterinärmedizin. Reibe A 45: 625-633.

Lauer S, Zanella A, Kortel A, Henke J, Scharvogel S, Unshelm J, Goldberg $M$, Eichinger $\mathrm{H}$, Petrowicz $\mathrm{O}$, Brill $\mathrm{T}$ and Erhardt W (1994). The CO2/O2-anaesthesia for castration of male piglets (preliminary results) Die Co 2/O 2-Anasthesie zur Kastration von mannlichen Ferkeln (vorlaufige Ergebnisse). Deutsche Tierarztliche Wochenschrift 101: $110-113$

Marx G, Horn T, Thielebein J, Knubel B and von Borell E (2003). Analysis of pain-related vocalization in young pigs. Journal of Sound and Vibration 266: 687-698.

Mench JA (2003). Assessing animal welfare at the farm and group level: a United States perspective. Animal Welfare 12: $493-503$.

Millman ST (2007). Sickness behaviour and its relevance to animal welfare assessment at the group level. Animal Welfare 16: 123-125.

Millman ST (2013). Behavioral responses of cattle to pain and implications for diagnosis, management, and animal welfare. Veterinary Clinics of North America-Food Animal Practice 29: 47-57.

Muhlbauer IC, Otten W, Lupping W, Palzer A, Zols S, Elicker S, Ritzmann M and Heinritzi K (2009). Investigation about $\mathrm{CO}_{2}$ gas anaesthesia as an alternative option for piglet castration without anaesthesia Untersuchung zur $\mathrm{CO}_{2}$-Narkose als eine Alternative zur betaubungslosen Kastration von Saugferkeln. Praktische Tierarzt 90: 460-464.

Mustafa RA, Santesso N, Brozek J, Akl EA, Walter SD, Norman G, Kulasegaram M, Christensen R, Guyatt GH, Falck-Ytter Y, Chang S, Murad MH, Vist GE, Lasserson T, Gartlehner G, Shukla V, Sun X, Whittington C, Post PN, Lang E, Thaler K, Kunnamo I, Alenius H, Meerpohl JJ, Alba AC, Nevis IF, Gentles S, Ethier MC, Carrasco-Labra A, Khatib R, Nesrallah G, Kroft J, Selk A, Brignardello-Petersen R and Schunemann HJ (2013). The GRADE approach is reproducible in assessing the quality of evidence of quantitative evidence syntheses. Journal of Clinical Epidemiology 66: 736-742; quiz 742 e $731-735$

Ochroch EA, Mardini IA and Gottschalk A (2003). What is the role of NSAIDs in pre-emptive analgesia? Drugs 63: 2709-2723.

Oxman AD, Schunemann HJ and Fretheim A (2006). Improving the use of research evidence in guideline development: 2. Priority setting. Health Research Policy and Systems 4: 14.

Rauch A and Sharp J (2005). Obioans' Attitudes about Animal Welfare: a Topical Report from the 2004 Obio Survey of Food, Agricultural and Environmental Issues. Columbus, $\mathrm{OH}$ : The Ohio State University, Social Responsibility Initiative, Department of Human and Community Resource Development

Rebecca L, Susanne Z, Andrea B, Andreas P, Mathias R and Karl $H$ (2009). Investigation about the use of analgesics for the reduction of castration-induced pain in suckling piglets. Berliner und Munchener Tierarztliche Wochenschrift 122: 325-332.

Reiner G, Schollasch F, Hillen S, Willems H, Piechotta M and Failing K (2012). Effects of Meloxicam and Flunixin on pain, stress and discomfort in male piglets during and after surgical castration. Berliner und Munchener Tierarztliche Wochenschrift 125: 305-314.

Author, A. (2012) Review Manager (RevMan) [Computer program]. Version 5.0. Copenhagen: The Nordic Cochrane Centre, The Cochrane Collaboration, 2008.

Rittershaus D, Waldmann KH, Schoen PC and Kietzmann M (2009). Topical anaesthetic techniques during castration of male suckling piglets. Journal of Veterinary Pharmacology and Therapeutics 32: 80-80.

Rutherford KMD (2002). Assessing pain in animals. Animal Welfare 11: 31-53.

Schonreiter S, Lohmuller V, Huber H, Zanella AJ, Unshelm J and Erhardt W (2000). Effects of $\mathrm{CO}_{2} / \mathrm{O}_{2}$-anaesthesia on behaviour, beta-endorphin- and cortisol concentrations of male piglets after castration Auswirkungen der CO2/O2Narkose auf das Verhalten sowie die beta-Endorphin- und Cortisolkonzentrationen mannlicher Saugferkel nach der Kastration. KTBL-Schrift 2000 391: 137-145.

Schunemann HJ, Fretheim A and Oxman AD (2006a). Improving the use of research evidence in guideline development: 10 . Integrating values and consumer involvement. Health Research Policy and Systems 4: 22.

Schunemann HJ, Fretheim A, Oxman AD and Research, WHOACoH (2006b). Improving the use of research evidence in guideline development: 1. Guidelines for guidelines. Health Research Policy and Systems 4: 13.

Schwab S, Follrich B, Kurtev V and Keita A (2012). Ketoprofen practical use and efficacy for post-surgical analgesia in piglet castration Ketoprofen - Einsatz und Wirksamkeit zur post-operativen Analgesie bei der Ferkelkastration. Tierarztliche Umschau 67: 207-213.

Singer NS, Mason M, Murphy JA, Raafat A, Singer IO, Stewart A and Watson WH (2006). Decision making processes of patients when asked to participate in a Haematology Phase III cancer clinical trial. British Journal of Haematology $\mathbf{1 3 3}$ 114-115.

Singer P and Mason J (2007). The Ethics of What We Eat: Why Our Food Choices Matter. Rodale 1594866872

Author, A. SurveyMonkey, http://www.surveymonkey.com (last visited [Dcc 2013]).

Sutherland MA, Davis BL, Brooks TA and Coetzee JF (2012). The physiological and behavioral response of pigs castrated with and without anesthesia or analgesia. Journal of Animal Science 90: 2211-2221.

Sutherland MA, Davis BL, Brooks TA and McGlone JJ (2010). Physiology and behavior of pigs before and after castration: effects of two topical anesthetics. Animal 4 2071-2079.

Swanson JC (2008). The ethical aspects of regulating production. Poultry Science 87: 373-379.

Temple D, Courboulay V, Manteca X, Velarde A and Dalmau A (2012). The welfare of growing pigs in five different production systems: assessment of feeding and housing. Animal 6: 656-667.

Tenbergen, R. (2012). Investigation of the Use of Analgesics at the Time of Castration and Tail-docking and Following Parturition for Improving Performance and Reducing Pain in Pigs. Master of Science in Population Medicine, University of Guelph.

Tonsor GT and Wolf CA (2010). Drivers of resident support for animal care oriented ballot initiatives. Journal of Agricultural and Applied Economics 42: 419-428.

Wavreille J, Danard M, Servais V, Art T, Nicks B and Laitat M (2012). Effect of preoperative meloxicam or tolfenamic acid administration on stress and pain induced by surgical castration in piglets Analgesie preemptive du porcelet avant la castration: comparaison de l'effet 
de l'acide tolfenamique et du meloxicam sur la douleur et le stress. Journées Recherche Porcine 44: 275-276.

White RG, Deshazer JA, Tressler CJ, Borcher GM, Davey S, Waninge A, Parkhurst AM, Milanuk MJ and Clemens ET (1995). Vocalization and physiological-response of pigs during castration with or without a local-anesthetic. Journal of Animal Science 73: 381-386.
Wright W and Middendorf G (2008). The Fight over Food: Producers, Consumers, and Activists Challenge the Global Food System. PA: Penn State Press, 0271032758.

Zols S, Ritzmann M and Heinritzi K (2006). Effect of a local anaesthesia in castration of piglets. Berliner und Munchener Tierarztliche Wochenschrift 34: 103-106. 